\title{
PCR-RFLP detection of point mutations in 23sr RNA gene responsible for clarithromycin resistance in Helicobacter Pylori isolates of Ahvaz, Iran
}

\begin{abstract}
Helicobacter pylori is the most common human pathogen and is the main cause of chronic gastritis, gastric ulcer and gastric malignancies. Clarithromycin is the key antibiotic in the treatment of Helicobacter pylori infections. Clarithromycin resistance is due to point mutations in the variable region of 23s rRNA peptidyl transferase, and the most important of which is the displacement of A-G at position 2143, 2142 (A2143G, A 2142G). The aim of this study was to determine the resistance of Helicobacter pylori isolated strains to Clarithromycin and subsequently to detect Clarithromycin resistant point mutations. 224 gastric biopsies were collected by endoscopy during 2016. Samples were homogenized and immediately cultivated on Colombia agar containing sheep blood and various antibiotics at $37^{\circ} \mathrm{C}$ under microaerophilic conditions. By using biochemical methods and identifying the glmM gene, Helicobacter pylori strains were confirmed. Standard strain ATCC26695 was used as control. The prevalence of resistance to clarithromycin was determined by E-test method based on CLSI standard. The MIC $\geq 1 \mu \mathrm{g} / \mathrm{ml}$ was considered as resistant. Existing point mutations were identified by the PCR-RFLP method followed by sequencing of 224 endoscopic specimens, 93 strains of $H$. pylori were identified. 49 strains $(52.7 \%)$ were resistant to clarithromycin. Prevalence of A2143G, A2142G, A2142C was $77.5 \%, 4.1 \%$ and $4.1 \%$, respectively. 7 samples $(14.2 \%)$ contained 2 types of mutations. The high prevalence of Helicobacter pylori resistance to clarithromycin reported in this study is a serious concern. This necessitates performing of genotypic and phenotypic Antibiotic susceptibility methods. In this study, the relationship between the resistance of Helicobacter pylori strains to clarithromycin and point mutations in 23 srRNA was fully demonstrated.
\end{abstract}

Keywords: Helicobacter pylori, clarithromycin, point mutation, PCR-RFLP
Volume 2 Issue 5 - 2017

\author{
Mansour Amin,' Ali Akbar Shayesteh,' \\ Amirarsalan Serajian' \\ 'Department of microbiology, Ahvaz Jundishapur University of \\ Medical Sciences, Iran \\ ${ }^{2}$ Research center for infectious diseases of digestive system \\ [Alimentary tract research center], Ahvaz Jundishapur University \\ of Medical Sciences, Iran
}

\begin{abstract}
Correspondence: Amirarsalan Serajian, Department of microbiology, Faculty of Medicine, Ahvaz Jundishapur University of Medical Sciences, Ahvaz, Iran, Tel +986I33330074, Fax
\end{abstract} +986133720160,Email seraj_amirarsalan@yahoo.com

Received: August 08, 2017 | Published: December 07, 2017

\section{Introduction}

Helicobacter pylori is a spiral-shaped gram-negative bacterium that infects half of the world's population and is the main cause of chronic gastritis, gastric ulcer and gastric malignancies including gastric adenocarcinoma and mucus-associated lymphoid tissue (MALT) lymphoma. ${ }^{1,2}$ Helicobacter pylori is the most common human pathogen and a successful pathogen and has been specifically transmitted to humans in early childhood and through the family and can persist for decades in the gastric mucosa despite inherent and acquired immune responses. ${ }^{3,4}$ The prevalence of bacteria in developing countries is between $70 \%-90 \%$, and in developing countries it is 35-40\%. ${ }^{5}$ During a Helicobacter pylori infection, persistent inflammation and abnormal epithelial proliferation might be the major causes of Helicobacter pylori associated gastric disorders. ${ }^{6,7}$ Successful bacterial eradication is an effective method not only for the improvement of peptic ulcer, but also for gastric cancer. Succeeded bacterial elimination reduces the inflammation and atrophy of the gastric mucosa and can be effective in reducing the incidence of peptic ulcer and gastric cancers associated with Helicobacter pylori infection. ${ }^{8}$ Helicobacter pylori eradication therapy is usually a combination of one proton pump inhibitor with several antibiotics such as clarithromycin, metronidazole, amoxicillin and tetracycline. ${ }^{9-11}$ Expecting an increase in the resistance of Helicobacter pylori to these antibiotics is due to an increase in the number of treated patients, incomplete contribution of patients during treatment and an increase in the use of antibiotics in recent years. ${ }^{9,10}$ The prevalence of resistance to mentioned drugs in different geographical areas is very different. Therefore, prior to administration of any drug for the treatment of Helicobacter pylori infections, it is necessary to determine the regional susceptibility pattern for each geographical region. ${ }^{9,12,13}$ Several factors have contributed to reducing the efficacy of current treatments on Helicobacter pylori infections, but antibiotic resistance is the first factor of this decline in the world. ${ }^{14}$

Helicobacter pylori rapidly becomes resistant to many antibiotics after treatment, which leads to incomplete elimination of bacteria and rapid return of disease. ${ }^{10,12}$ Clarithromycin is the key antibiotic in the treatment of Helicobacter pylori infection, which is due to the bactericidal effect of the drug on the bacteria. ${ }^{11,15,16}$ Resistance to Clarithromycin is due to the lack of binding of the drug to the $23 \mathrm{~s}$ rRNA of the bacterial ribosome, which is caused by the occurrence of point mutations in the variable domains of the peptidyl transferees of $23 \mathrm{~s}$ rRNA. Several point mutations have been reported in about clarithromycin resistance, but the most important of which is the transition of A-G at position 2143 and 2142 (A2143G, A2142G). ${ }^{11,15-18}$ Although these mutations are responsible for most of the primary resistance to clarithromycin, each of them is specifically associated with different MIC values. The effect of the A2143G mutation on the outcome of the treatment is much greater than other mutations and is associated with a lower eradication rate. ${ }^{19,20}$ The resistance of Helicobacter pylori strains to antibiotics is determined in clinical specimens by standard methods such as Agar dilution, Microbroth dilution, Disk diffusion and E-test. These phenotypic methods are highly effective in isolating susceptible and resistant strains, but are 
time consuming and unable to detect resistance-inducing mutations. Among these methods, the E.Test is a simple, and easy, but expensive method to determine the MIC for most antibiotics. Genotypic methods such as Real Time PCR, Sequencing, RFLP require lesser time than phenotypic methods, and are capable of identifying a variety of resistance-causing mutations. Genotypic methods have limited efficiency because of insufficient data about the mechanism of bacterial resistance to some antibiotics. ${ }^{11,16,17}$ Among genotypic methods, PCR-RFLP is highly efficient in detection of 23s rRNA gene mutations and its application to find resistance to clarithromycin leads to more effective and better management of Helicobacter pylori infections. ${ }^{16}$

\section{Aim of study}

The aim of this study was to determine the resistance of Helicobacter pylori isolates to clarithromycin and subsequently to identify the mutations responsible for clarithromycin resistance.

\section{Materials and methods}

\section{Sample collection, isolation of strains and storage in a freezer}

224 gastric biopsy samples taken from patients referring to the Endoscopy Division Unit of Imam and Mohr hospitals in Ahvaz city(southwest of Iran) during 2016 were collected in sterile tubes containing BHI broth (Merck-Germany) and 5\% non Activated fetal calf serum (Baharafshan-Iran) and transferred on ice to the Department of Microbiology, Faculty of Medicine. The samples were fragmented and homogenized on a sterile glass slide by a bistoury blade and were cultivated on Colombia agar (Merck-Germany) containing 7\% fresh sheep blood, 5\% inactivated fetal calf serum (BaharafshanIran) And several antibiotics including Vancomycin (10mg/l-Sigma-
USA), Amphotericin B (4mg/L-Sigma-USA), Trimethoprim (5mg/LSigma-USA) and Polymyxin (10mg/L-Sigma-USA). The inoculated plates were incubated for 3 to 5 days at $37^{\circ} \mathrm{C}$ under microaerophilic conditions ( $7 \% \mathrm{Co} 2,5 \%$ oxygen, saturated humidity) produced by Anaerocult $\mathrm{C}$ system(Merck-Germany). ${ }^{21}$ The isolates were recognized as H. pylori by urease, catalase, oxidase positive and gram negative staining tests. Afterward a bacterial suspension was prepared in the BHI broth (Merck-Germany), containing 30\% sterile glycerol and $10 \%$ inactivated fetal calf serum and were stored in $-80^{\circ} \mathrm{C}$. Before the endoscopy, a questionnaire was filled out by the patients. Also, patients who took clarithromycin for two weeks before endoscopy were excluded from the study. ${ }^{21}$

\section{DNA extraction}

DNA was extracted from all 93H. pylori grown isolates using DNA extraction kit (Roche-Germany) according to the manufacturer's instruction. To prevent the possible error in the diagnosis of bacterium, amplification of glmM gene was done by PCR method. Extracted DNA stored in $-20^{\circ} \mathrm{C}$ until the test was performed..$^{11,22}$ First, to confirm the isolation of Helicobacter pylori, glmM (ureC) gene was amplified by PCR, resulting in a 294bp fragment. This gene is a house kipping gene which found in all strains of Helicobacter pylori. PCR conditions included denaturation at $94^{\circ} \mathrm{C}$ for 60 seconds, annealing at $57^{\circ} \mathrm{C}$ for 90 seconds, and extension at $72^{\circ} \mathrm{C}$ for 120 seconds in 40 cycles. The final extension at $72^{\circ} \mathrm{C}$ for 7 minutes was done to complete the PCR process. Master mix (Sinaclon-Iran) of reaction contains $800 \mu \mathrm{mol}$ of dNTPs, $2.5 \mu \mathrm{g} \mathrm{mgcl} 2,50 \mu \mathrm{m}$ buffer, $2.5 \mu \mathrm{g}$ of Taq enzyme, $1.8 \mu \mathrm{l}$ of each of the primers (metabion-Germany) and $0.7 \mu 1$ template DNA in total volume of $20 \mu \mathrm{l}$. Obtained PCR products were electrophoresed on $2 \%$ agarose gel with ethidium bromide. ${ }^{23}$ The name and sequence of the primers, the size of PCR product and the name of the gene have been shown in (Table 1).

Table I Product size and primers used for amplification of GLMM gene

\begin{tabular}{llll}
\hline Gene name & Primer sequence & Product size(bp) & Reference \\
\hline \multirow{2}{*}{ gImM } & F- AAGCTTTTAGGGGTGTTAGGGGTTT & 294 & 24
\end{tabular}

\section{Evaluation of strains resistance clarithromycin using E. test \\ to Amplification of variable domain of peptidyl transferase gene}

For H. Pylori isolated strains, the antibiogram test was performed using the E. test method with clarithromycin strips (Lioflichem-Italy) on muller-Hinton agar (Merck-Germany) enriched with 7\% sheep blood and MIC of Clarithromycin is determined for all strains. At first, a suspension of pure H.Pylori colonies in sterile physiologic saline with turbidity equals to $3 \mathrm{McF}$ arland tube $\left(9 \mathrm{x} 10^{8} \mathrm{CFU} / \mathrm{ml}\right)$ was prepared, and inoculated on enriched Muller-Hinton agar with a cotton swab immersed in bacterial suspension. After drying the surface of the medium, the clarithromycin strips were placed on the inoculated medium and were incubated at $37^{\circ} \mathrm{C}$ for 72 hours under microaerophilic conditions. If the MIC values were greater than or equal to one microgram per liter, the strains were considered resistant to Clarithromycin. ${ }^{21}$

The amplification of variable domain of peptidyl transferase gene by PCR method involves the initial denaturation for 4 minutes at $94^{\circ} \mathrm{C}$ and 32 cycles of denaturation at $94^{\circ} \mathrm{C}$ for 40 seconds, annealing at $61.5^{\circ} \mathrm{C}$ for one minute, and extension at $72{ }^{\circ} \mathrm{C}$ for one Minutes. At the end of the reaction, a final extension process takes place for 7 minutes at $72^{\circ} \mathrm{C}$. The master mix of reaction (Sinaclon-Iran) contains $16.5 \mu \mathrm{l}$ of distilled water, $3.3 \mu \mathrm{l}$ buffer, $2.5 \mu \mathrm{l}$ dNTPs, $0.2 \mu \mathrm{l}$ of Taq enzyme, $1.8 \mu \mathrm{l}$ of each of the primers (metabion-Germany) and $0.7 \mu l$ of the template DNA in a total volume of $25 \mu$. PCR products were electrophoresed on $1.5 \%$ agarose gel containing Safe Stain (Sinaclon-Iran). ${ }^{25}$ The name and sequence of the primers, the size of PCR products and the name of the gene have been shown in Table 2 .

Table 2 Product size and primers used for amplification of peptidyl transferee's gene

\begin{tabular}{lllc}
\hline Gene name & Primer sequence & Product size(bp) & Reference \\
\hline \multirow{2}{*}{ Peptidyl transferase of $V$ domain of 23srRNA } & F-CCACAGCGATGTGGTCTCAG & 425 & 26 \\
& R-CTCCATAAGAGCCAAAGCCCC & & \multirow{2}{*}{} \\
\hline
\end{tabular}




\section{Determination Clarithromycin RFLP}

Among the strains that were resistant to clarithromycin, PCR-RFLP was performed to identify point mutations. First, a fragment of $425 \mathrm{bp}$ length from the variable domain of 23s rRNA peptidyl transferase was amplified by PCR. Afterward PCR products were digested using BSAI and BBSI (Thermo scientific-Lithuania) restriction enzymes and obtained fragments were detected by electrophoresis on $1.5 \%$ agarose gel. Using the size and number of fragments obtained, the point mutations responsible for the resistance to clarithromycin in strains were defined resistant in E-test has been identified. ${ }^{9,16,25,26}$ Also, if there are other types of point mutations, these mutations will be identified by the Sequencing method using ABI system (AbottUSA). For enzymatic digestion of PCR products gained from peptidyl transferees variable region amplification, mixed $2 \mu 1$ of PCR product with $8 \mu 1$ of distilled water and $2 \mu$ of digestive enzymes, for the BsaI enzyme, the mixture was incubated for 30 minutes at $37^{\circ} \mathrm{C}$ and for BBSI, 24 hours at $37^{\circ} \mathrm{C}$. Then digested products were electrophoresed in $1.5 \%$ agarose. ${ }^{9}, 15,16$

\section{Results \& discussion}

In this cross-sectional study, 224 patients with gastric problems referring to the endoscopy division unit of Imam and Mehr hospitals of Ahwaz city were examined. Of 224 endoscopic samples, 93 strains $(41.5 \%)$ of Helicobacter pylori were isolated by culture (Figure 1). Of these, 51(55\%) were isolated from men and $42(45 \%)$ of female. Patients age for men were 25-82years old and women were 24-79years old. The isolates were recognized as H. Pylori by urease, catalase, oxidase positive and gram negative staining tests. To confirm Helicobacter pylori strains, a PCR test was conducted to amplify the UREC gene (glmM) (Figure 2). The clinical diagnosis given by endoscopy includes gastritis, peptic ulcer, duodenal ulcer and gastric cancer. Results showed that 49 isolates $(52.7 \%)$ of 93 strains of $H$. Pylori were detected resistant to clarithromycin by E.Test. Resistant strains have a MIC of 1 to $96 \mu \mathrm{g} / \mathrm{ml}$ and all susceptible strains have MIC $<1 \mu \mathrm{g} / \mathrm{ml}$.In the next step, a $425 \mathrm{bp}$ fragment from the variable region of 23 srRNA was amplified by the PCR method. The resultant PCR product was affected by the endonuclease enzymes of BSAL and BBSL. The PCR product from strains containing A2143G mutation when affected by the BSAL enzyme produce two fragments of 304bp and 101bp (Figure 3), and strains contains A2142G mutation when affected by the BBSL enzyme produce two fragments of $332 \mathrm{bp}$ and 93bp (Figure 4). All Clarithromycin resistant strains produced 425bp fragment in the PCR. In this study, among 49 clarithromycin resistant isolates were affected by enzymes, 38 strains (77.5\%) had A2143G mutation and 2 strains (4.1\%) had A2142G mutation. Seven strains (14.2\%) had both A2143G and A2142G mutations. Sequencing was performed for two strains lacking both mutations, but were resistant to Clarithromycin in the E.Test method, sequences of these strains were analyzed using MEGA7 software: molecular evolutionary genetics analysis version 7 for bigger datasets (2016), and Both strains had A2142C mutations. Helicobacter pylori standard strain 26695 was used as control strain in the study.

Helicobacter pylori resistance to antibiotics is expanding in most parts of the world, including Iran,. Clarithromycin is one of the most important components used in the treatment regimens of Helicobacter pylori infections, and expanded resistance to this drug has become a serious concern for the eradication of this bacterium. ${ }^{27}$ The use of culture-based methods to determine the sensitivity of the drug to $H$. pylori is very difficult, because the bacteria are fastidious and require a long time to grow on selective culture media. ${ }^{28,29}$ Helicobacter pylori resistance to clarithromycin varies in different parts of the world, for example, in southern Europe 30\% and in the United States, between $15 \%$ and $30 \%,{ }^{18}$ While in the Asian countries such as Vietnam and Iran , $42.4 \%$ \& $31.7 \%$ respectively. ${ }^{27,30}$ In this study, isolated Helicobacter pylori strains displayed resistance to clarithromycin in 49/93 cases $(52.7 \%)$ using the E.Test method, which is consistent with some studies in different parts of the world and incompatible with some others. For example, Fan et al. In a study in Vietnam in 2015, reported the resistance rate of Helicobacter pylori strains to clarithromycin $42.4 \%,{ }^{30}$ which is close to the results of this study. Also, in a study by Rashid et al. ${ }^{31}$ In Pakistan in 2014, resistance to clarithromycin was $47.8 \%,{ }^{31}$ which is largely similar to the current study. Asaka \& colleagues in Japan in 2010 also reported the resistance rate to clarithromycin of $27.7 \% .^{32}$

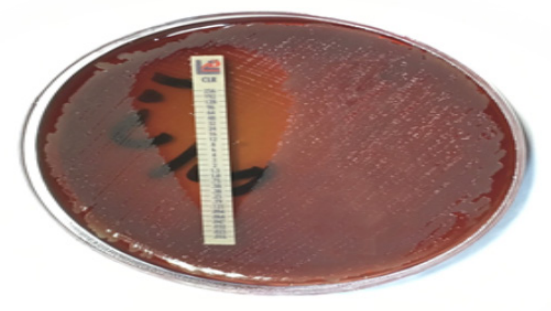

Figure I H.Pylori sensitive strain to clarithromycin (E.Test).

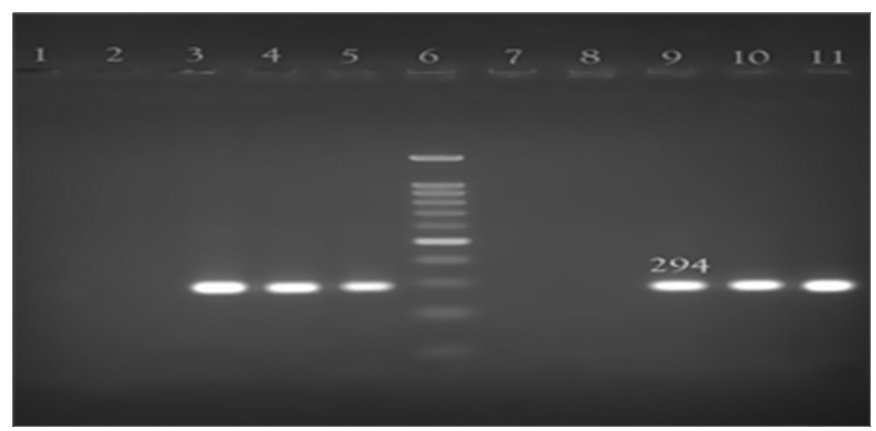

Figure 2 Gel electrophoresis of PCR products of 23srRNA Gene. Lane 6, I00bp DNA ladder, lanes 3, 4,5,9, I0, I I H. Pylori isolates. Lane I negative control, lanes 2,7,8 Non H.Pylori bacteria.

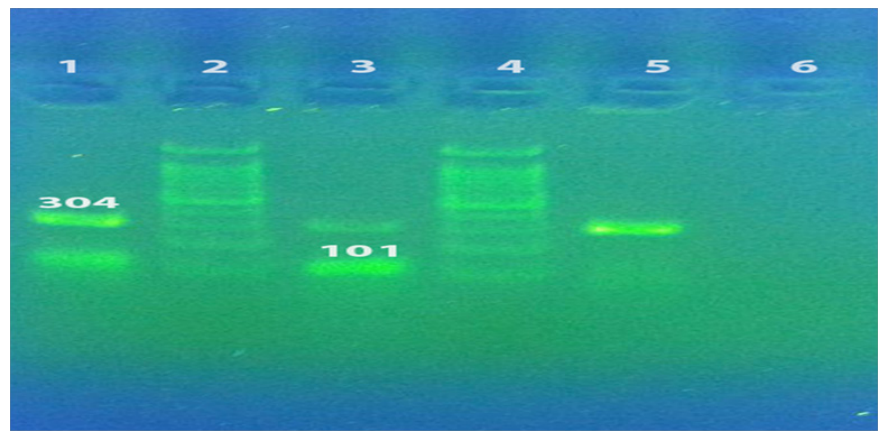

Figure 3 RFLP analysis of $23 \mathrm{~S} r$ RNA to detect the A2I43G mutation using Bsal restriction enzyme. Lanes 1,3 and 5: Digestion products of two clarithromycin resistant strains with Bsal. Lane 2\&4100bp DNA ladder, lane 6 negative control. 


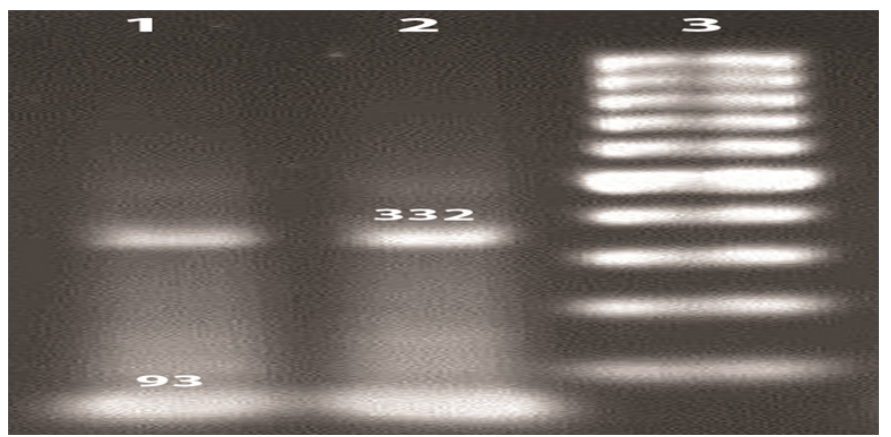

Figure 4 RFLP analysis of 23S $r$ RNA to detect the A2I42G mutation using Bbsl restriction enzyme. Lanes I and 2: Digestion products of two clarithromycin resistant strains with Bbsl, lane 3 l00bp DNA ladder.

In different regions of Iran, Helicobacter pylori resistance to clarithromycin was different, for example, in Tehran in 2005, this rate was reported by Mohammadi et al., ${ }^{33} 20 \%$ while reported rate by Abdullahi et al. ${ }^{27}$ was $31.7 \%{ }^{27}$ According to the high level of H. pylori resistance to clarithromycin in this study it seems to be due to the high consumption of macrolides in the treatment of respiratory diseases at this point in Iran because of severe respiratory disorders and also the high use of clarithromycin in the treatment of Helicobacter pylori infections because of high incidence of gastric disorders in residents of the studied area. Versalovich et al. were the first researchers to show that Helicobacter pylori resistance to clarithromycin is associated with point mutations in the variable region $23 \mathrm{srRNA}$. They also discovered that point mutations that cause the A to G transition in the 23srRNA sequence occur at 2143 and 2142 positions. ${ }^{27}$ In this study, using PCR-RFLP method, two common mutations of A2143G and A2142G were detected in Helicobacter pylori clarithromycin resistant strains and in cases where these mutations were not found, other mutations were identified by sequencing method. In all resistant strains, at least one mutation from point mutations exists and therefore, complete association between the resistance of Helicobacter pylori strains to clarithromycin and the presence of point mutations in this study was confirmed. The prevalence of $\mathrm{A} 2143 \mathrm{G}$ and $\mathrm{A} 2142 \mathrm{G}$ mutations in this study was $77.5 \%$ and $4.1 \%$ respectively, which was compatible with the results of Nishizawa et al. ${ }^{32}$ in Japan, Agudo et al. ${ }^{15}$ In Spain And Doroud et al. ${ }^{26}$ in Iran, ${ }^{15,26,32}$ but differs from the results of the studies by Kelzwick et al. In Poland and De Francesco et al. ${ }^{13}$ In Italy. ${ }^{13,16}$ This indicates the existence of a geographical difference in the level of resistance to clarithromycin and this fact highlights the importance of determining the resistance of regional strains of Helicobacter pylori to the selection of appropriate therapeutic methods. It should be noted that the mutations reported in this study are not the only point mutations known in the resistance of Helicobacter pylori to clarithromycin, and several other point mutations have been reported elsewhere in the world. In addition, a small part of the Helicobacter pylori resistance to clarithromycin is due to the Efflux system, which makes bacteria send out the macrolide.

\section{Conclusion}

The high prevalence of Helicobacter pylori resistance to clarithromycin reported in this study is a serious concern that should be considered by physicians in determining the patient's drug regimen. This necessitates performing of genotypic and phenotypic Antibiotic susceptibility methods. In this study, the relationship between the resistance of Helicobacter pylori strains to clarithromycin and point mutations in 23srRNA was fully demonstrated. Also, the results of this study showed that the resistance of Helicobacter pylori strains to clarithromycin in Iran has been rising and this has reduced the effectiveness of this drug.

\section{Acknowledgements}

The authors of this article will appreciate the cooperation and support of the physicians and employees of the endoscopic departments of Imam and Mehr Hospitals in Ahvaz.

\section{Ethical approval}

This study was approved by ethics committee of the jundishapur university of medical science in ahvaz-southwest of Iran (IR.AJUMS. REC.1395.581).

\section{Conflict of interest}

Author declares that there is no conflict of interest.

\section{References}

1. Chunliang G, Yaling L, Yan Li, et al. Genotyping analysis of Helicobacter pylori using multiple-locus variable-number tandem-repeats analysis in five regions of China and Japan. BMC Microbiology. 2011;11:197-203.

2. Edith Vega A, Cortiñas TI, Puig ON, et al. Molecular characterization and susceptibility testing of Helicobacter pylori strains isolated in western Argentina. Int J Infect Dis. 2010;14(3):85-92.

3. Salama NR, Hartung ML, Müller A. Life in the human stomach: persistence strategies of the bacterial pathogen Helicobacter pylori. Nat Rev Microbiol. 2013;11(6):385-399.

4. Yong X, Tang B, Li BS, et al. Helicobacter pylori virulence factor CagA promotes tumorigenesis of gastric cancer via multiple signaling pathways. Cell Commun Signal. 2015;13:30.

5. Alhussaini MS. Prevalence of Helicobacter pylori among patients with different gastrointestinal disorders in Saudi Arabia. Med J Indonesia. 2016;25(4):214-220.

6. Malfertheiner P, Megraud F, O Morain CA, et al. Management of Helicobacter pylori infection-the Maastricht IV/Florence Consensus Report. Gut. 2012;61(5):646-664.

7. Franceschi F, Tortora A, Gasbarrini G, et al. Helicobacter pylori and extragastric diseases. Helicobacter. 2014;21(1):52-58.

8. Shiota S, Cruz M, Jimenes Abreu JA, et al. Virulence genes of Helicobacter pylori in the Dominican Republic. J Med Microbiol. 2014;63(9):1189-1196.

9. Wolle K, Leodolter A, Malfertheiner P, et al. Antibiotic susceptibility of Helicobacter pylori in Germany: stable primary resistance from 1995 to 2000. J Med Microbiol. 2002;51(8):705-709.

10. Wu H, Shi XD, Wang HT, et al. Resistance of Helicobacter pylori to metronidazole, tetracycline and amoxicillin. Journal of Antimicrobial Chemotherapy. 2000;46(1):121-123.

11. Tanih NF, Ndip RN. Molecular Detection of Antibiotic Resistance in South African Isolates of Helicobacter pylori. Gastroenterology Research and practice. 2013. p. 6.

12. Wu W, Yang Y, Sun G. Recent Insights into Antibiotic Resistance in Helicobacter pylori Eradication. Gastroenterology Research and Practice. 2012. p. 8.

13. De Francesco V, Giorgio F, Hassan C, et al. Worldwide H. pylori Antibiotic Resistance.A Systematic Review. J Gastrointestin Liver Dis. 2010;19(4):409-414. 
14. Kim SY, Choi DJ, Chung JW. Antibiotic treatment for Helicobacter pylori: Is the end coming? World J Gastrointest Pharmacol Ther 2015;6(4):183-198.

15. Agudo S, Pérez-Pére Guillermo Z, et al. Rapid detection of clarithromycin resistant Helicobacter pylori strains in Spanish patients by polymerase chain reaction-restriction fragment length polymorphism. Rev Esp Quimioter. 2011;24(1):32-36.

16. Klesiewicz K, Nowak P, Karczewska E, et al. PCR-RFLP detection of point mutations $\mathrm{A} 2143 \mathrm{G}$ and $\mathrm{A} 2142 \mathrm{G}$ in $23 \mathrm{~S}$ rRNA gene conferring resistance to clarithromycin in Helicobacter pylori strains. Acta Biochim Pol. 2014;61(2):311-315.

17. Owen RJ. Molecular testing for antibiotic resistance in Helicobacter pylori. Gut. 2002;50(3):285-289.

18. Cerqueira L, Fernandes RM, Ferreira RM, et al. Validation of Fluorescence In Situ Hybridization Method Using Peptide Nucleic Acid Probes for Detection of Helicobacter pylori Clarithromycin Resistance in Gastric Biopsy Specimens. J Clin Microbiol. 2013;51(6):1887-1893.

19. Papastergiou V, Georgopoulos SD, Karatapanis S. Treatment of Helicobacter pylori infection: Meeting the challenge of antimicrobial resistance. World J Gastroenterol. 2014;20(29):9898-9911.

20. Testerman TL, Morris J. Beyond the stomach: An updated view of Helicobacter pylori pathogenesis, diagnosis, and treatment. World $J$ Gastroenterol. 2014;20(36):12781-12808.

21. Forbes BA, Sahm DF, Weissfeld AS. Bailey \& Scott's Diagnostic microbiology. 12th ed. USA; Mosbey-Elsevier: 2007.

22. Vaziri F, Najar Peerayeh S, Alebouyeh M, et al. Diversity of Helicobacter pylori genotypes in Iranian patients with different gastroduodenal disorders. World J Gastroenterol. 2013;19(34):5685-5692.

23. Ferreira Menoni SM, Alves Bonon SH, Robilota Zeitune JM, et al. PCRBased Detection and Genotyping of Helicobacter pylori in Endoscopic Biopsy Samples from Brazilian patients. Gastroenterology Research and Practice. 2013. p. 8.
24. Santos JC, Ladeira MSP, Pedrazzoli J, et al. Relationship of IL-1 and TNF- $\alpha$ polymorphisms with Helicobacter pylori in gastric diseases in a Brazilian population. Braz J Med Biol Res. 2012;45(9):811-817.

25. Li Juan Z, Yan Qiang H, Bing Pu C, et al. Helicobacter pylori isolates from ethnic minority patients in Guangxi:Resistance rates,mechanisms,and genotype. World Journal of Gastroenterology. 2014;20(16):4761-4770.

26. Doroud D, Mohajerani N, Massarrat S, et al. Are molecular methods appropriate substitutions for traditional antimicrobial assays in detecting Helicobacter pylori antibiotic resistance in Iranian clinical trials? The 4th national biotechnology congress، Islamic republic of iran-kerman. 2005.

27. Abdollahi H, Savari M, Zahedi MJ, et al. Detection of A2142C, A2142G, and $\mathrm{A} 2143 \mathrm{G}$ Mutations in 23s rRNA Gene Conferring Resistance to Clarithromycin among Helicobacter pylori Isolates in Kerman, Iran. Iran J Med Sci. 2011;36(2):104-110.

28. Chattopadhyay S, Patra R, Ramamurthy T, et al. Multiplex PCR assay for rapid detection and genotyping of Helicobacter pylori directly from biopsy specimens. J Clin Microbiol. 2004;42(6):2821-2824.

29. Miftahussurur M, Yamaoka Y. Diagnostic Methods of Helicobacter pylori Infection for Epidemiological Studies: Critical Importance of Indirect Test Validation. BioMed Research International. 2016. p. 14.

30. Safavi M, Sabourian R, Foroumadi A. Treatment of Helicobacter pylori infection: Current and future insights. World J Clin Cases. 2016;4(1):5-19.

31. Rasheed F, Campbell BJ, Alfizah H, et al. Analysis of Clinical Isolates of Helicobacter pylori in Pakistan Reveals High Degrees of Pathogenicity and High Frequencies of Antibiotic Resistance. Helicobacter 2014;19(5):387-399

32. Nishizawa T, Suzuki H. Mechanisms of Helicobacter pylori antibiotic resistance and molecular testing. Front Mol Biosci. 2014;24(1):19.

33. Mohammadi M, Doroud D, Mohajerani N, et al. Helicobacter pylori antibiotic resistance in Iran. World $J$ Gastroenterol. 2005;11(38):6009-6013. 